\title{
RECONSTRUCTING THE HISTORY OF SOCIOLOGICAL THEORY
}

\section{Roscoe C. Hinkle}

Ohio State University

Mid-American Review of Sociology, 1982, Vol. VII, No. 1:37-53

It is curious that sociologists have never engaged in any serious or sustained discourse on the criteria for constituting histories of sociological theory-thought, though the interest in such history generally dates back at least to Giddings and Small. From the earliest volume by Bristol on Social Adaptation in 1915 up to Turner's and Beeghley's The Emergence of Sociological Theory in 1981, the prefaces, prologues, and introductions are conspicuously devoid of any consideration of the general problem of just how such undertakings are to be constituted. Other literature is pervasively lacking in the treatment of the problem. Even Merton's chapter "On the History and Systematics of Sociological Theory," which introduces his On Theoretical Sociology in 19.67, does not directly tackle the problem. And with the exception of one roundtable in 1978, the same void has been characteristic of the American Sociological Association meetings since at least World War II. To use the words of recent French structuralism, a curious silence has prevailed. It is the purpose of this paper to end that silence, to induce reflection, and to stimulate and promote the beginnings of theoretical discourse on the problem of the nature of an acceptable history of sociological theory-thought.

Admittedly, several somewhat unusual circumstances may have occasioned this current lamentable state of affairs. Unlike other fields, the history of sociological theory seems to owe its existence more to pedagogical than to research considerations. (Undeniably, sociologists do engage in research in the history of theory but it has had little impact on the writing of textbooks. And publishers have not been especially inclined to question current conventions of textbook writing in the field.) Then, too, the raising of the issue as this paper does may seem to articulate disconcerting implications for the boundaries between history 
and sociology or for the primacy of professional commitments. (All the way up to the early 1940 s, sociologists were seriously exercised about their adherence to science as the study of the general, universal, common and recurrent, which they regarded as characteristically and categorically different from history as the study of the particular, concrete, non-recurrent, unique or eventful.) But certainly some recent historians and sociologists have begun to draw on one another's disciplines with little fear of professional disloyalty. Undeniably, too, the call for a sociological history of sociological theory should also aid in dispelling hesitation.

In any event, some candid and unflinching stocktaking does seem to be required. Accordingly, the author has undertaken an examination of the volumes on the history of theory written since World War II. By virtue of the concern with an extended range of historical attention, those books devoted solely to current or contemporary sociological theory have been excluded. The number of volumes thus remaining to be scrutinized is just under twenty (as specified below). On the basis of the inquiry, two major modes of writing the history of sociological theory, each with substantial disadvantages, if not defects, are evident.

Of the two types, the history of theory as the history of great theorists encompasses the larger number of works. It includes: Barnes' (ed.) An Introduction to the History of Sociology (1948), Mihanovich's Social Theorists (1953), Timasheff's Sociological Theory (1955), Coser's Masters of Sociological Thought (1971, 1977), Collins' and Makowsky's The. Discovery of Society (1972), Larson's Major Themes in Sociological Theory (1973), Jesser's Social Theory Revisited (1975), Timasheff's-Theodorson's Sociological Theory (1976), Bierstedt's American Sociological Theory (1981), Ritzer's Toward an Integrated Sociological Paradigm (1981), Turner's and Beeghley's The Emergence of Sociological Theory (1981), and Zeitlin's Ideology and the Development of Sociology (1981).

The histories of theory of this type seem to have the following major disadvantages, if not defects:

1. They tend logically to become a sociological version of the "great man" theory of history. Such history of theory tends to be constituted of a sequence of great men, eminent figures, gifted or unique personalities. The distinctiveness of each one is emphasized. Ideas tend to become associated with the unique biography of the person and explanation or interpretation tends to proceed accordingly. If carried to its logical extreme, this approach individualizes, personalizes, or social psychologizes history rather than sociologizing or structuralizing it.

2. They are inclined to use the vocabulary of concepts of each particular theorists as the point of departure, which in the absence of any qualifying considerations, obstructs systematic comparison. Nothing intrinsic to the approach requires systematic identification and analysis of similarities. However, it is noteworthy that three of the most popular volumes of this type do seek to introduce ad hoc qualifying devices. In his revision of the Timasheff text, Theodorson retains the earlier general notion of sociological theory and its features which he can use to introduce comparison and generalization as he chooses. By adopting a uniform presentational scheme (especially the biography in context, the intellectual setting, and social milieu), Coser can resort to generalizations between figures as he desires. Turner and Beeghley invoke a similar expedient requiring that each theorist's intellectual origins, his major works, and his contributions to sociological modes and principles be examined.

3. They are likely to pursue analysis at a surface, explicit, apparent, or immediate level rather than at a subsurface, implicit, removed, or deep level. In the absence of the imposition of additional criteria, basic assumptions are not subject to systematic and continuous examination. Nothing intrinsically demands consideration of the underlying social epistemology or methodology (e.g., empiricism vs. idealism or positivism vs. humanism). Nor do questions have to be raised about the continuity or discontinuity of the nature of the social with biophysical nature or about its materialist or idealist quality or qualities.

4. They tend to ignore the possible existence and detection of pervasive continuities and discontinuities across time. Such questions as might concern major differences between French and German sociological theory up to World War I or the nature of the continuities or discontinuities between American theory 
before World War I and that between World War I and II are not likely to be raised. At best, attention can be directed to particular theorists.

5. They seem to equate historicality with the assumption (illusion?) of the passage of time in chronological sequence. Demonstration of actual intellectual differences (or similarities) in accordance with specific dates is unnecessary. All that needs to be shown is that the theories of figures succeed one another chronologically or in some rough "before-after" or "earlier-later" fashion. So, Theodorson (1976:12) simply asserts three periods in sequence. Turner and Beeghley (1981:xiii, xv, xvii) arrange theorists by the categories: "The Birth of the Sociological Tradition" (Comte, Spencer, Marx), "The Maturing Tradition in Europe" (Weber, Simmel, Durkheim, Pareto), and "The Emerging Tradition in America" (Mead only).

6 . They pervasively avoid concern with the criteria in terms of which inclusion in the "universe" of sociological theory occurs. (Admittedly, Turner and Beeghley are unusally explicit. They recognize that they are including only figures who can be shown to contribute to their positivistic deductive-nomological notion of theory. But they are unaware of or ignore the problem they have created for Simmel and Weber.) Generally, the histories of great theorists seem to imply universality. At least, initially (i.e., in their earlier figures) such histories include prominent theorists of diverse national and intellectual antecedents. But their later and especially terminal figures tend to be peculiarly drawn from the U.S. The trend of the past of theory curiously culminates in American theorists. The history of theory as the history of great theorists ulitmately seems to have a curious resemblance to the (earlier) universal histories of progress culminating in Western Europe and especially the U.S. Indeed, sociological theory has a progressive-like (or "progressive"?) trend eventuating in American theorists. (But any surprise must turn to chagrin: our histories of theories as theorists have been constituted by American theorists.)

In contrast, the histories of theory focusing on ideas are fewer in number. They include: Martindale's The Nature and
Types of Sociological Theory (1960, 1981), Nisbet's The Sociological Tradition (1966), Sorokin's Sociological Theories of Today (1966), Kinloch's Sociological Theory (1977), Bottomore's and Nisbet's (eds.) A History of Sociological Analysis (1978), and Wiley's "The Rise and Fall of Dominating Theories in American Sociology" in Snizek's Fuhrman's, and Miller's (eds.) Contemporary Issues in Theory and Research (1979).

The histories of theory of this second type pervasively seem to have two major defeats:

1. The "idea" which is made the point of departure is not precisely defined and is not itself susceptible of internal differentiation. For all of Nisbet's efforts, the "unit-ideas" (community, authority, status, the sacred, and alienation) of his The Sociological Tradition are peculiarly global and diffuse, are independent of and discrete from one another, and have no distinctive combinatory or integrative qualities. Though obviously borrowed from Kuhn, Kinloch's paradigms of his Sociological Theory are not defined in terms of definite and precise features. "Organic," "conflict," and "social behaviorism" have no specific referents. What constitutes the "theory" of Wiley's "dominating theories" is left unanswered. The chapter units or subjects which comprise the Bottomore and Nisbet volume can perhaps best be characterized as sociological stances or orientations. But the defining characteristics are implict rather than explicit and thus the orientations as such are vague and ambiguous. Sorokin's Sociological Theories of Today endeavors to be systematic, without being entirely successful. Attempting to classify sociological theories in terms of their stance on the question of the part-whole relationship in the social, he distinguishes (1966:37-41, 133-136) nominalistic (-singularisticatomistic) theories from (realistic-universalistic-holistic or) systemic theories. In contrast, Martindale essentially recognizes (1981:xiii) that sociological theories have in fact dealt both with epistemological-methodological and (social) ontological problems, i.e., how the social is known and studied and what the nature of the social is. For the former problem, he identifies (1981:xiv-xv) two positions (scientific and humanistic) and for the latter two also (elementaristic and holistic). And so four 
types of theory derive: humanistic elementarism, humanistic holism, scientific elementarism, and scientific holism. (But even Martindale seems to have provided only the most minimal, elementary bases for a classification of types of theory.)

2. Curiously, these histories of theory emphasizing ideas are disconcertingly insensitive to the passage of time. In Nisbet's The Sociological Tradition, the years through which the unitideas are analyzed, i.e., 1830-1900, are apparently regarded as an undifferentiated whole or continuity. Nisbet offers no argument as to why the years thereafter should be construed differently. Kinloch's text deals with time arbitrarily: he distinguishes a period of "traditional sociological theory" from a period of "contemporary sociological theory." But he is vague about what temporally differentiates one from the other. The chapters of Bottomore's and Nisbet's (eds.) A History of Sociological Analysis are arranged to suggest a chronological sequence of sociological orientations from the eighteenth century (first chapter), the eighteenth and nineteenth centuries (chapters two and three), nineteenth and twentieth centuries (chapters four through eight), and up to the relatively contemporary twentieth century (chapters nine through fourteen). The reader is to assume temporal sequence. Like The Sociological Tradition, Sorokin's Sociological Theories of Today is not genuinely sensitive to the passage of time. He treats $(1966: 6-11)$ the years 1925 to 1965 as an undifferentiated whole-without justification for its separation from the previous period, other than the fact that the terminal date of his -earlier Contemporary Sociological Theories was 1925. Finally, Martindale achieves a sense of temporal succession by presenting and analyzing the ideas of major figures from each of the four types of theory (including also subvarieties) in chronological sequence.

With a critique of the major features of the two modes of constituting the history of sociological theory completed, it is now appropriate to turn to the proposal embodied in the author's Founding Theory of American Sociology 1881-1915 (1980). Chapters one and three (especially pages 7-11, 59-65, 72-75) do indicate that its procedure aligns it substantially with the second rather than the first type of organizing the history of theory. It does focus on ideas and especially those involved in specifying basic, underlying assumptions. Its proposal to use a classificatory-periodicizing scheme derives from the initial decision that a history of (American) sociological theory would have to be envisaged rigorously in terms of what sociological theory in its most comprehensive sense has meant in the past and means today. Thus, both an extensive and intensive scrutiny of past literature (back to the founding figures) on the meaning(s) of the term was undertaken. (Undeniably, some preoccupation with etymology was involved and some attempt was made to pursue the intellectual leads of Timascheff's Sociological Theory [p.11], Sorokin's Social and Cultural Dynamics [Vol. 2] and his Sociological Theories of Today, and Martindale's The Nature and Types of Sociological Theory and his chapter in his edited Functionalism in the Social Sciences, 1965). The immediate question of what makes sociological theory distinctively "sociological" and "theoretical" (i.e., a "theory") led back logically first to a consideration of "soci-ology" as the noun form of the adjective "sociological," i.e., to the notion of the discipline and profession characteristically endeavoring (to know and) to study the social in its most comprehensive sense. More ultimately, concern was directed to the two basic problem-domains of: 1) the nature of sociological knowledge and the method of study (social epistemology-methodology or the theory-theories of social epistemology-methodology), and 2) the nature of the social or social reality (social ontology or the theory-theories of social ontology). Each of these two problem-domains is further specifiable into a series of additional questions or issues and their related possible answers or positions. (For the justification of the terms used, consult Founding Theory, p. 331, note two.) On this foundation of classificatory-periodicizing scheme was developed (first in a preliminary, abbreviated form in an article in The Journal of the History of the Behavioral Sciences, Vol. II (2), April, 1975:108-109, and later in a more extended, complete form in Founding Theory, pp. 60-64). Its fundamentals are represented below: 
Essentials of a Scheme for Classifying and Periodicizing Macro-Theories in the History of American Sociology

I. Criteria for the analytical classification and periodicization of sociological theory

A. The nature of theory in sociological theory (implying an expanded concern with social epistemological-methodological theory)

B. The nature of the social in sociological theory (implying an expanded concern with social ontological theory)

II. Theory about knowing-studying the social (social epistemologymethodology)

A. Bases of knowing the social (social knowledge)

1. Sensation (empiricism) vs. reason (rationalism)

2. Feeling - empathy - "nacherleben"

B. Methods for studying the social

1. Similarity-dissimilarity of methods for studying the social biophysical sciences: positivism (as similar) vs. humanism (as dissimilar)

2. Focus of methods on: parts (as methodological atomism or individualism) vs. wholes (as methodological holism or collectivism)

C. Epistemological-methodological implementation in formulating theory as:

1. Explanation (positivist, objectivist): physical model, deductive-nomological, universal

2. Interpretation (humanistic, intersubjectivist): language communication basis; ethnomethodological-phenomenological-hermeneutics construed; meaningfully limited.

III. Theory about the (known) social (social on tology)

A. Conceptions of the social (as):

1. (Interpersonal and/or multipersonal) Relations(s) or relationship(s)

2. (Interpersonal and/or multipersonal) Activity(ies)

The character of the activity: 'behavior,' 'action,' 'interaction,' 'sociation' (association-dissociation)

b. Forms of activity: (processes of) cooperation, competition, conflict, accommodation, assimilation, etc.

3. (Persisting, structured) Group

a. Basis: interpersonal and/or multipersonal relations and activities which persist and become structured b. Kinds: dyads to society
B. Relations of the social to other phenomena and/or realities 1. The social as a domain, realm, or system

a. As a type of object (or object-like) entity in nature (as constituted of distinctive forces, for instance)

b. As a distinctive whole possessing some autonomy from nature

2. Relations of the non- and near-social to social phe nomena

a. Non-human biophysical

b. Human: 1) organic, 2) psychic, 3) cultural, 4) near social: as plurals, categories, aggregates

C. Nature of the social

1. As a form of reality

a. Preponderantly 'pure' forms (monisms): social sociological 'materialisms' vs. social-sociological 'idealisms'

b. Substantially 'mixed' forms (dualisms, etc., of social 'materialisms' and social 'idealism')

2. In relation to the (logical-ontological) part-whole or whole-part controversy ('universals-particulars,' 'holismatomism')

a. Social nominalism (and neo-nominalism)/social atomism

b. Social realism (and neo-realism)/social holism

D. Major problems and their interrelations in the study of the social

1. Genesis (origins, emergence)

2. Stasis (statics, stability, persistence, structure)

3. Dynamis (dynamics, instability, change, variation, transformation)

This scheme is central both to the particular historical inquiry embodied in the author's Founding Theory and to his general proposal for reconstructing the history of sociological theory, which entails certain evident (hopefully, positive and advantageous) features:

1. It demands that the history of theory become a researchoriented field and not merely-and certainly not primarily-a pedagogically-sustained field. Any attempt to use the classificatory scheme demands research at two levels. One is at the level of the documents of particular sociologists whose work or works ranging across a particular interval of time is ascertained to be classifiable as general or macro-theory. Initially, a statement of 
each sociologist's theory is worked out. It is cast in terms of how he envisages the major problems of theory, what its division are, the major concepts used, the evidence accepted (and acceptable), conclusions (and criteria for drawing such conclusions), etc. Such individual statements (amounting to fifty to one hundred typescript pages) were composed for Sumner, Ward, Giddings, Ross, Small, and Cooley. Only then was an attempt made to discern similarities and dissimilarities, to generalize, and to translate the findings into the terms of the scheme. Of course, translation into the vocabulary of the scheme entails research at a second level, which has been so important for Founding Theory.

2. Ideas and especially basic assumptions are of central concern. The focus is on ideas, notions, and concepts as they are explicitly and implicitly interrelated with one another in sets and unities and as they are cast in opposition to still others. Furthermore, the interest lies not in an individual theorist's ideas but with his and others' relation to one another in a common sociological position, stance, or orientation.

3. Comparative study is indispensable. Use of the scheme facilitates the analysis and characterization of the intellectual positions of a plurality of theorists across time. It seeks to identify and typify both similarities and dissimilarities and thus (technically) enables both comparisons and contrasts to be drawn. The scheme basically directs attention to how the social is to be known and studied (i.e., a social epistemology and methodology) and what the nature of the social is (i.e., a social ontology, especially as the social is defined and then revealed in the positions taken on the problems of genesis, structure, and change). The contents of chapters four through eleven of Founding Theory follow accordingly.

4. The proposed approach requires identification of common intellectual positions or orientations, some or one of which is dominant during a particular interval of time and for which particular theorists become crucial expositors and/or representative figures. Allusions to particular theorists in terms of such general and dominant orientation(s) become justifiable in terms of their significance in the orientation. Presumably, their statements are important in the development of characterizations and generalizations about the nature of general or macro-theory within a particular time-interval. However, it is also necessary to recognize that dominant orientations (or even important subordinate orientations) ordinarily do not involve monolithic uniformity. Knowing just how much internal variation exists within a stance can become significant in terms of subsequent theoretical developments. What may seem to be minor differences at one point in time may under different circumstances become major and consequential.

5. By virtue of the identification and characterization of such common and general intellectual orientations, some one(s) of which is (are) dominant, periodicization can be effected. History of theory is no longer merely the sequential arrangement of theories of prominent theorists in (chronological) time. Instead, it becomes a succession of periods, in which a dominant orientation (perhaps achieving the status of an orthodoxy) may be followed in turn by a transition involving controversy (and heterodoxy) among several contending stances, out of which is generated finally another dominant orientation and so on. Founding Theory does characterize early American theory as committed to "evolutionary naturalism" as the dominant stance from about 1881 to 1915 . Subsequent continuing research suggests that the years from about 1915 to 1945 may be best characterized as a transitional period in which basic assumptions were in such a state of controversy that no dominant stance could or did appear. However, the action frame of reference was expounded by several prominent theorists, including Parsons. That frame of reference provided an intellectual platform for the development of structural-functionalism, the orientation assuming increasing prominence and eventually dominance from about 1945 to 1965. (It does appear that the years from about 1965 to the present again constitute another interval of controversy between and among opposing stances, no one of which has yet decisively assumed dominance.) Certainly, it is important to examine the events occurring in systems external to theory (i.e., its mileux) at the time one period seems 
to be ending and another beginning. (See Founding Theory, pp. 300-301 and item No. 8 below.)

6. Detection of both theoretical discontinuities and continuities between and among periods is assumed to be necessary. Periodicization does signify discontinuity as is evident in the decline-demise of an old and the rise-ascendancy of a new orientation. However, the scheme also makes it possible to ascertain just what assumptional similarities have persisted beneath or even in terms of the sequence of (different and thus discontinuous) dominant stances. (Consult Founding Theory, pp. 229 and pp. 306-327 for voluntaristic nominalism as a persisting social ontological assumption.) In the long perspective, i.e., over several periods, minority of subordinate orientations may be consequential.

7. The proposed approach envisages the possibility of an explanatory account and toward that end facilitates resort to hermeneutics and structuralism. For the former, it is to be noted that the initial studies of individual theorists use their published works as so many texts which must be synthesized into more or less integrated statements for each one. Such statements must be couched within the problem formulation and the terminology used by or characteristic of the theorist. Attention must be given both (to) what he or she accepts and rejects, endorses and repudiates, agrees and disagrees. Gradually, a whole is inferred and constructed from the parts and, conversely, parts from an assumed whole. The procedure does involve the well-known hermeneutic circle. As in a particular text or unit of theoretical discourse, so in the composite work (of separate texts), the presupposition of a certain whole is implied in the recognition of the parts. And reciprocally, the construing of the parts implies a construing of the whole. Meaningfulness is involved in the shuttling-back-and-forth between whole and part and part and whole. Parts are interpreted in terms of a whole and a whole in terms of parts.

But once the translation has been made to the language or terminology of the scheme, the individual statements have necessarily become parts or aspects of a more generalized stance, position, or orientation which has been formulated in terms that are generic to (general) theoretic discourse in sociology or antecedent disciplines. What Levi-Strauss endeavored to do for myths and kinship, the classificatory-periodicizing scheme attempts to do for sociological theory. The scheme identifies the basic opposing positions in the realms of epistemologymethodology and social ontology (re: the notion of the social, genesis of the social, structure of the social, and change in the social). It is of the utmost significance that any generalized theoretical orientation which is identified and characterized through use of the scheme is already cast in terms of certain basic oppositions, contrasts, and polarities. Accordingly, even though the particular distinctions (each of which is part of a paried antithesis) have importance, what is of considerably greater consequence is the perculiar logic, form, or structure of their relationship in constituting the whole of a theoretical orientation. So the very nature of the classificatory scheme is such as to embody the fundamentals of and provide access to structuralism. (Note that this argument was not developed in Founding Theory: it alluded only to a possibility of a genetic structuralism, pp. 324-328.)

8. Formulation of an explanation is held to require the study of evidence from at least two periods and from a series of related contexts. Explanation is intrinsically general and thus evidence about the dominance of one orientation from more than one period (i.e., of a change) is needed. (What is to be explained may include, therefore, dominant orientations subordinate orientations, persistence of assumptional similarities across several periods, etc.)

Formulation of such explanation must thus include not only the present character of the theory (and past theory), but appropriately analyzed information about a series of relevant contexts: the character of other fields of sociology and their personnel, changes within the structure of sociology as a profession; shifts in the other social sciences, the natural sciences, the humanities, knowledge in general (both in the sense of disciplines and professions); alternations in academia; the nature of the relation of the professorate to the salaried professions, 
the free professions, and to the occupational structure in general (as linked to social class, etc.), the nature of American society and culture, including basic values. (It is necessary to note that the contexts included in Founding Theory are provided only for orientations of readers and not for subsequent construction of an explanation.)

9. Critique is also possible (such as critical theory might offer). Once the relevance of particular contexts and their interrelations, and thus the directionality of their influence, has been ascertained for a given dominant stance, the reverse possibility might be entertained. Thus, it should be feasible to inquire into the (obverse) problem of just what relevance the dominant theoretical stance has for the maintenance of the status quo in American society and culture. So critique might be undertaken. (Among other things, it should be illuminating to discover the extent to which such an intellectual enterprise converges with or diverges from the analysis of the Schwendingers' The Sociologists of the Chair.)

10. In the broadest sense, the proposed mode of constituting a history of theory demands that the history being constructed be explicitly situated, both spatially and temporally. A universal history of theory is an illusion, for a history is always such within some particular universe of discourse (e.g., that of the U.S. or Europe) over a particular range of time. (Europe and the United States seem to comprise more or less separate universes of discourse or traditions in the social sciences. Even though they have. influenced one another, they have been substantially independent.) Nevertheless, this mode of historiography also contemplates the possibility of undertaking comparative studies of histories, e.g., the histories of American theory and of European theory might be compared and contrasted. But initially a more circumscribed step-by-step procedure seems advisable, i.e., first the study and characterization of the history of one is to be undertaken (and, indeed, has been undertaken); then the other next; and finally, on the basis of the two separate studies, it should become possible to compare and contrast the histories of the two in context.
11. Finally, the approach advocated recognizes that no history of sociological theory is constituted enternally-for all time. As the eventuality of the future becomes the actuality of the present, change occurs and history has to be rewritten in terms of such now existing present(s). At the minimum, additional periods are required and must be added to prior formulations. At the maximum, it may be necessary to reconsider the character of one or more parts of the scheme, to further differentiate and extend it on the basis of past distinctions or even to reconstruct and reconstitute portions thereof. (Past history is not to be construed as sacred and neither is the scheme. See the last sentence of the first paragraph of note two, chapter three Founding Theory, p. 331.)

Hopefully, the silence has been broken. The two extant major modes of constituting the history of sociological theory have been articulated and subjected to criticism in the perspective of a third approach, the features of which have just been outlined. Only as the potentiality of the future becomes the actuality of the present will the interested know whether or not research becomes a significant force in reconstructing a field heretofore so pervasively dominated by pedagogical concerns.

\section{REFERENCES}

Barnes, Harry Elmer (ed.)

1948 An Introduction to the History of Sociology. Chicago: The University of Chicago Press.

Bierstedt, Robert

1981 American Sociological Theory: A Critical History. New York: Academic Press.

Bottomore, Tom and Robert A. Nisbet (eds.)

1978 A History of Sociological Analysis. New York: Basic Books.

Bristol, Lucius Moody

1915 Social Adaptation. Cambridge, Mass.: Havard University Press.

Collins, Randall and Michael Makowsky

1972 The Discovery of Society. New York: Random House.

Coser, Lewis

1971, Masters of Sociological Thought: Ideas in Historical and Social

1977 Context. New York: Harcourt Brace Jovanovich.

Hinkle, Roscoe C.

1975 "Basic Orientations of the Founding Fathers of American Sociology," Journal of the History of the Behavioral Sciences 11: 107-122. 
Hinkle, Roscoe C.

1980 Founding Theory of American Sociology 1881-1915. Boston: Routledge and Kegan Paul.

Jesser, Clinton Joyce

1975 Social Theory Revisited. Hinsdale, Ill.: Dryden.

Kinloch, Graham C.

1977 Sociological Theory: Its Development and Major Paradigms. New York: McGraw-Hill.

\section{Larson, Calvin J.}

1973, Major Themes in Sociological Theory. New York: David McKay. 1977

Levi-Strauss, Claude

1967 Structural Anthropology. [1958] Translated by C. Jacobson and B.G. Schoepf. Garden City, N.Y.: Anchor Books.

Martindale, Don

1960, The Nature and Types of Sociological Theory. Boston: Hough-

1981 ton-Mifflin.

1965 "Limits of and Alternatives of Functionalism in Sociology." Pp. 144-162 in Don Martindale (ed.) Functionalism in the Social Sciences. Philadelphia: The American Academy of Political and Social Science.

Merton, Robert K.

1967 On Theoretical Sociology: Five Essays, Old and New. New York: Free Press.

Mihanovich, Clement S.

1953 Social Theorists. Milwaukee, Wis.: Bruce.

Nisbet, Robert A.

1966 The Sociological Tradition. New York: Basic Books.

Ritzer, George

1981 Toward an Integrated Sociological Paradigm: The Search for an Exemplar and an Image of the Subject Matter. Boston: Allyn and Bacon.

Schwendinger, Herman and Julia R. Schwendinger

1974 The Sociologists of the Chair: A Radical Analysis of the Formative Years of North American Sociology (1883-1922). New York: Basic Books.

Sorokin, Pitirim A.

1928 Contemporary Sociological Theories. New York: Harper.

1937 Social and Cultural Dynamics, Vol. 2, Fluctuations of Systems of Truth, Ethics, and Law. New York: American Book.

1966 Sociological Theories of Today. New York: Harper.

Temasheff, Nicholas S.

1955, Sociological Theory: Its Nature and Growth. New York: Random

1957, House.

1967
Temasheff, Nicholas, George A. Theodorson

1976 Sociological Theory: Its Nature and Growth. New York: Random House.

Turner, Johathan $\mathrm{H}$. and Leonard Beeghley

1981 The Emergence of Sociological Theory. Homewood, Ill.: Dorsey. Wiley, Norbert

1979 "The Rise and Fall of Dominating Theories in American Sociology." Pp. 47-79 in William E. Snizek, Ellsworth R. Fuhrman, and Michael K. Miller (eds.) Contemporary Issues in Theory and Research: A Metasociological Perspective. Westport, Conn.: Greenwood Press.

Zeitlin, Irving $M$

1968, Ideology and the Development of Sociological Theory. Engle1981 wood Cliffs, N.J.: Prentice-Hall. 